\title{
Reduced winter chill as a means to improve the production potential of late day-neutral strawberry cultivars
}

\author{
N. Gallace ${ }^{1}$, P. Lieten ${ }^{2}$, M. Boonen ${ }^{1}$ and D. Bylemans ${ }^{1,3}$ \\ ${ }^{1}$ PCfruit, Department of Field Research Berry Fruit, Sint-Truiden, Belgium \\ ${ }^{2}$ Fragaria Holland, Horst, The Netherlands \\ ${ }^{3}$ KU Leuven, Department of Biosystems, Leuven, Belgium
}

\section{Summary}

The main production peak of day-neutral strawberry cultivar 'Verity' is typically late compared with other day-neutral cultivars grown in Belgium. Delay in the onset of flower initiation in spring means that a dip in production is experienced between autumn and spring initiated crops. Not only is continuity of supply interrupted, but more importantly, total yield potential is limited, preventing widespread adoption of such varieties by growers. Results of this trial elucidate that prolonged exposure to chill (hours $<7^{\circ} \mathrm{C}$ ) during storage as a frigo plant is responsible for this delay, and that plants of 'Verity' receiving less winter chill provide higher earlier yields and a shorter delay between autumn and spring initiated crops.

Keywords

Fragaria $\times$ ananassa, chilling, branched crowns, stolon, flower induction

\section{Introduction}

Day-neutral strawberry cultivar 'Verity' is best regarded for its excellent presentation, superior shelf life, tolerance to a range of foliar and root pathogens as well as its consistent flavour and favourable berry size grading. Despite its many positive attributes, the predominant harvest period for 'Verity' occurs in August and September. Preferably, consistent summer supply commencing in July and even the end of June is necessary for varieties in Belgium to be considered commercially interesting. Expected yields for 'Verity' from a standard frigo plant planted in the soil in March/April are considered average and production ranges from 0.8 to $1.3 \mathrm{~kg}$ per plant, depending on the season. Frigo plants make up the largest portion of day-neutral plantings in the soil. They are convenient, can be stored until the growing conditions become favourable, are cheap to buy and their use is standard practice throughout Central Europe. Frigo plants accumulate large amounts of chill both in the field during autumn prior to digging and also during cold storage at $-1.5^{\circ} \mathrm{C}$. Typically, day-neutral frigo plants acquire anywhere up to 3,000 hours below $7^{\circ} \mathrm{C}$ prior to planting. Varieties such as 'Verity' however, become vegetative in response to the excess chill and produce an abundance of stolons. The resulting vegetative reaction tends to delay harvest and even prevent plants from initiating flowers necessary for adequate yields during the season. Previous trials have concentrated on the isolated and interactive effects of temperature and day length in day-neutral strawberry cultivars often in climate chambers (Sonsteby

\section{Significance of this study}

What is already known on this subject?

- Chill is understood to be a precursor for optimum growth and development in short day strawberry cultivars. Similarly, chill is understood to stimulate vegetative vigour in perpetual flowering strawberry types.

\section{What are the new findings?}

- The observations in this trial confirm that favouring vegetative development prevents generative growth necessary to achieve adequate commercial yields. Excess winter chill of perpetual flowering types leads to delayed flower initiation in the spring and over stimulation of stolon production following planting. Plants receiving less chill give earlier production, more flower trusses, less stolons, and higher yields.

What is the expected impact on horticulture?

- These observations have significant future implications for the ways perpetual flowering strawberry types are propagated and raised leading up to planting, particularly throughout Central Europe where frigo plants are common practice and winter temperatures are typically low.

and Heide, 2009; Sonsteby and Nes, 1998), however the information generated does not have immediate practical significance for growers. In this trial the benefit of reducing chill prior to planting for tray plants of 'Verity' is demonstrated.

\section{Materials and methods}

On $19^{\text {th }}$ August 2015 tray plants of 'Verity' were propagated using fresh cuttings planted in $250 \mathrm{cc}$ standard 9-hole trays. A mix of $100 \%$ blonde peat was amended with 2.5 $\mathrm{kg} \mathrm{m}^{-3}$ Osmocote Bloom ${ }^{\circledR}$ (cuttings were immediately covered with a white plastic film until adequately rooted). Plants were split up into five groups which each received 0,250 , 500 or 1,000 chill hours (hours below $7^{\circ} \mathrm{C}$ ). Plants remained in the nursery under natural field conditions until the nominated number of chill hours was reached. When the individual groups had received adequate chill exposure, they were transferred to a heated glasshouse with a minimum set point of $8^{\circ} \mathrm{C}$ where they remained until two weeks before planting (on 19th April 2016). Control plants (frigo tray [250 cc] plants) were stored at $-1.5^{\circ} \mathrm{C}$ from December until planting. They received a total of 3,360 chill hours. All plants were planted on raised beds in the soil (plant density 3.25 plants 
TABLE 1. Fruit size grading $(\%>$ and $<31 \mathrm{~mm})$, and number of flower trusses and stolons per plant.

\begin{tabular}{lcccc}
\hline Hours of chilling $\left(<7^{\circ} \mathrm{C}\right)$ & $\begin{array}{c}\text { Tot truss number } \\
\text { per plant }\end{array}$ & $\begin{array}{c}\text { Total stolon number } \\
\text { per plant }\end{array}$ & Class 1 $\%>31 \mathrm{~mm})$ & Class 2 $(\%<31 \mathrm{~mm})$ \\
\hline 0 & $26.3 \mathrm{a}$ & 11.1 & 70 & 18 \\
250 & - & - & 68 & 20 \\
500 & $24.3 \mathrm{~b}$ & 11.3 & 65 & 20 \\
1000 & $22.5 \mathrm{c}$ & 17.3 & 70 & 17 \\
\hline
\end{tabular}

Data are means; different letters in the same column indicate significant differences at $P \leq 0.05$.

$\mathrm{m}^{-2}$ ). The plants received an additional 474 hours of field chill after planting, which was beyond the control of the experiment. 'Walk-in' rain shelters were placed at the beginning of July (cladding: hyti tunnel diffused $120 \mu$ ). During the course of the season, total fruit weight $\left(\mathrm{g} \mathrm{pl}^{-1}\right)$, size grading (class two $<31 \mathrm{~mm}$ and class one $>31 \mathrm{~mm}$ diam.), harvest pattern, and truss and stolon number was recorded. Each treatment group was replicated four times. Each replicate contained 42 plants. The plots were arranged in a completely randomised experimental design.

\section{Results}

\section{Plant growth habit}

Overwintered tray plants with more chill had greater root development and were more vegetative than plants with less chill at planting. Several weeks after planting, however, plants with less chill had become visibly more vegetative with comparatively more 'branch crowns'.

\section{Truss number}

The average number of trusses per plant significantly increased with decreasing chill (Table 1). Each 500 hour incremental decrease in winter chill gave a corresponding increase of two trusses per plant. The difference in truss number per plant was significant for treatment groups 0,500 and $1,000(\mathrm{P} \leq 0.05)$.

\section{Fruit size grading}

The relative percentage of class one fruit compared to class two fruit remained the same regardless of chill. There was no effect of reduced chill on average fruit size observed in this trial (Table 1).

\section{Total fruit weight and production pattern}

All treatment groups gave a dip in production after the autumn-initiated trusses were picked (data not shown). Plants with less chill had a shorter delay following the first flush and went on to produce much larger production peaks for the rest of the season (Table 2). This effect translated to significantly higher total plant yields. The relationship between decreased exposure to winter chill and increasing total plant yield appeared linear.

\section{Discussion}

Adequate exposure to chill in short day crops is necessary for adequate fruit size and yield. It is also important for supplying vegetative vigour necessary to support normal growth and development of autumn initiated flowers. If chill in short-day cultivars is inadequate, fruits are often small and plants develop slower and more poorly (Lieten, 1997). The importance of chill is similarly assumed for day-neutral strawberry types however unlike short days, frigo plants of day neutrals at planting contain fewer flower trusses. Day neutrals therefore have a relatively low fruit load at the commencement of the growing season. Chill in the case of day-neutrals aids in the development of these autumn initiated trusses, however it also hinders subsequent initiation of trusses in the spring. Among short-day cultivars repeat flowering after the main crop rarely occurs when accumulated winter chill is adequate. A perpetual flowering behaviour in short days is however observed on occasions when winter chill is lacking. One could reasonably suggest that this reaction to chill observed in short day cultivars is essentially the same as what is being observed in day-neutrals. Our results suggest that increasing chill in day-neutral cultivars delays the onset of flower initiation in spring by eliciting a vegetative response in the plant.

\section{Stolon development versus side crown development}

In the current trial, reducing chill in 'Verity' led to plants that produced less stolons compared to those exposed to more chill. Following planting, groups with less chill were more inclined to produce branch crowns rather than stolons which led to plants that appeared more vegetative in the early growing season. This observation was unexpected since in short-day cultivars higher winter chill is associated with greater vegetative development. Greater vigour in chill trials generally report on stolon length, truss length or the stretching of petioles, which is relevant for optimizing subsequent fruit quality. In the current trial however observations regarding vegetative differences related mainly to leaf number and overall biomass. Whilst leaf number was not counted in this trial, differences were visually apparent. Stolons of highly chilled plants were systematically removed. Branched crowns however of less chilled plants went on to initiate flowers of the following production peaks, thus

TABLE 2. Average monthly contribution to total yield $\left(\mathrm{kg} \mathrm{pl}^{-1}\right)$ for each treatment group.

\begin{tabular}{|c|c|c|c|c|c|}
\hline & \multicolumn{5}{|c|}{ Hours $<7^{\circ} \mathrm{C}$} \\
\hline & 0 & 250 & 506 & 1,000 & 3,360 \\
\hline June/July & 0.317 & 0.300 & 0.340 & 0.200 & 0.143 \\
\hline August & 0.973 & 0.770 & 0.757 & 0.694 & 0.604 \\
\hline September & 0.549 & 0.475 & 0.394 & 0.342 & 0.465 \\
\hline Total & 1.839 & 1.545 & 1.491 & 0.236 & 1.212 \\
\hline
\end{tabular}




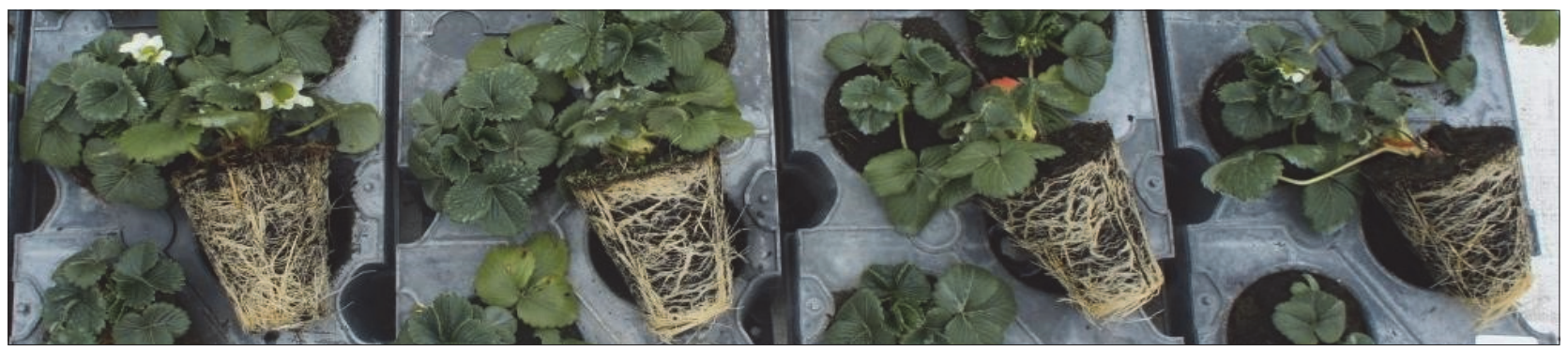

FigURE 1. Plants before planting on 19 April. From left to right $1000,500,250,0$ chill hours $<7^{\circ} \mathrm{C}$.

providing higher volumes of early fruit compared to higher chilled groups and therefore enabled plants to continue producing comparatively higher volumes for the rest of the season. It might therefore appear that chilling can inhibit flower initiation as is reported in the literature (Tomohiro and Yasaburo, 1990). It is also possible, however, that delayed flower initiation is an obvious consequence of stolon formation at the expense of branched crown development, in which case, any initiated flowers or potential flower initiation sites are removed and thus alternative flower initiation sites within the plant must be found. In any case an increasing gap in production between autumn and spring initiated crops is experienced as more winter chill is applied. This in turn puts a negative skew on the harvest pattern and an overall delay results.

Whilst we have explained that lesser chilled plants after planting progressed faster and more generatively than chilled groups, it should be mentioned that higher chilled groups also had a longer time on the tray field. Plants left longer to develop on the tray field under natural field conditions continued to grow and build a bigger plant compared to plants that were placed at earlier intervals in the heated glasshouse. This difference in plant development was visually obvious during the entire overwintering period until the time of planting (Figures 1 and 2).

\section{Inflorescence growth and development}

All branch crowns terminate in an inflorescence so it is no surprise that lesser chilled groups also experienced a comparative increase in flower truss number. Increased truss number resulting from reduced chill in this trial was directly responsible for the increase in total plant yield. This is

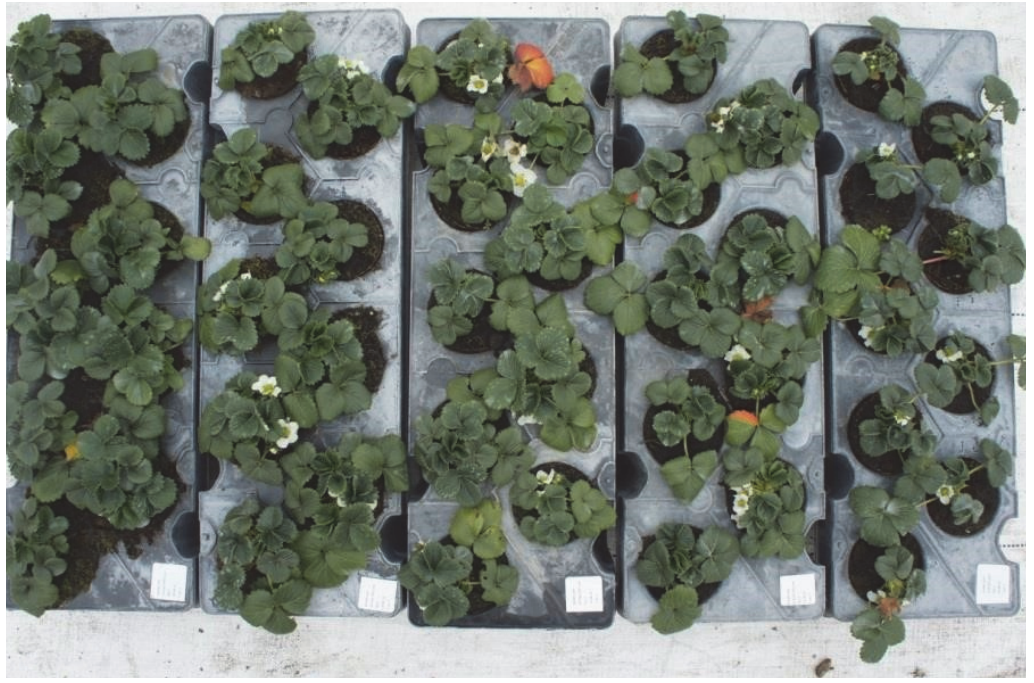

Figure 2. Plants before planting on 19 April. From left to right 1000, 750, $500,250,0$ chill hours $<7^{\circ} \mathrm{C}$. perhaps also in part why fruit size grading remained constant across the treatments since truss architecture was unaffected by varying chill. Fruit development in day-neutrals is gradual compared to short day crops where the fruit load and thus demand for assimilates is high. A comparatively lower fruit load in day-neutrals could also help to explain why normal fruit development and size grading was achieved regardless of reduced winter chill. The findings of this research did not associate lowered chill in day neutrals with a corresponding reduction in fruit size as is typical for short-day cultivars.

\section{Root growth and plant establishment}

Tray plants in autumn and early winter which received more chill also experienced stronger root development. This is ordinarily important for the build-up of reserve carbohydrates necessary for successful long-term frigo storage. In the case of 'warm trays' however where plants are held during the winter in a semi-active state, the need for starch reserves is less important. In fact, too strong and tight root development led to plants that established more poorly when planted in the soil. These root systems stayed bound to the original pot form and adventitious root growth in the surrounding soil was limited. Similarly tightly bound root volumes of higher chilled plants were also more challenging to irrigate. Higher root masses also had a higher demand for water. This created more volatility in the moisture profile of the root volume and from a practical perspective was more difficult to maintain. For these reasons we maintain that lower chilled plants with less dense root masses are more interesting to consider in future warm overwintering trials.

\section{Further limitations in knowledge}

Whilst these initial trial results from 2016 on 'Verity' are encouraging, future trials need to focus on improving the viability of overwintering tray plants in a glasshouse and also better understand the conditions necessary to favour the generative response in day-neutrals. A better understanding of the conditions that favour side crown over stolon development will not only result in reduced costs for the grower but also increase potential yields. Further weakness in current understanding includes a lack of knowledge about the effect of field chill after planting and also the various growing conditions leading up to planting in the harvest season. Knowledge about improved tray plant establishment in soil would also assist in the successful transfer of technology as would more specific trials on the effects on other commercially grown day neutral varieties. 


\section{Conclusions}

Results of this trial reveal that 'Verity' plants receiving the lowest number of chill hours ( 0 ) gave the earliest production, the highest total yield, the most flower trusses and the least number of stolons. With each successive increase in acquired chill the earliness, total yield, and flower trusses reduce and conversely the number of stolon's increases. These results have significance for growers wishing to commercially exploit late day neutral varieties in the future.

In practice, day-neutral types in Central Europe are in fact over-chilled, giving rise to plants that give a suboptimal performance. The ramifications of over-chilling are well highlighted by the results in this trial which mainly include delayed flower initiation in the spring and over-stimulation of stolon production following planting.

\section{Acknowledgments}

We wish to acknowledge the support of Fragaria Holland, in particular Van Alphen plant nursery.

\section{References}

Lieten, P. (1997). Effects of chilling and night break treatment on greenhouse production of 'Elsanta'. Acta Hortic. 439, 633-640. https://doi.org/10.17660/ActaHortic.1997.439.105.

Smeets, L. (1982). Effect of chilling on runner formation and flower initiation in the everbearing strawberry. Sci. Hortic. 17(1), 43-48. https://doi.org/10.1016/0304-4238(82)90060-7.

Sonsteby, A., and Nes, A. (1998). Short days and temperature effects on growth and flowering in strawberry (Fragaria $\times$ ananassa Duch.). J. Hortic. Sci. Biotechnol. 73(6), 730-736. https://doi.org/10.1080/1 4620316.1998.11511040.

Sonsteby, A., and Heide, O.M. (2009). Long day flowering response of everbearing strawberries. Acta Hortic. 842, 777-779. https://doi. org/10.17660/ActaHortic.2009.842.170.

Tomohiro, Y., and Yasaburo, O. (1990). Effects of chilling history on successive flowering and runner development of everbearing and non-everbearing strawberry cultivars. J. Japanese Soc. Hortic. Sci. 59(2), 357-363. https://doi.org/10.2503/jjshs.59.357.

Received: Nov. 17, 2017

Accepted: Dec. 17, 2018

Addresses of authors:

N. Gallace ${ }^{1, *}$, P. Lieten ${ }^{2}$, M. Boonen ${ }^{1}$ and D. Bylemans ${ }^{1,3}$

${ }^{1}$ PCfruit, Department of Field Research Berry Fruit, Sint-

Truiden, Belgium

${ }^{2}$ Fragaria Holland, Horst, The Netherlands

${ }^{3}$ KU Leuven, Department of Biosystems, Leuven, Belgium

* Corresponding author;

E-mail: Nicole77gallace@pcfruit.com.be

Tel.: +32 (0)488107360 